\title{
Komunikasi Bahasa Sindiran dalam Seloka Pak Pandir dan Pak Kaduk
}

\author{
NORDIANA AB JABAR \\ Universiti Malaysia Kelantan \\ MOHD FARADI MOHAMED GHAZALI \\ Universiti Sultan Zainal Abidin
}

\begin{abstract}
ABSTRAK
Karya kreatif puisi tradisional Melayu merupakan rakaman kisah hidup yang penuh dengan teladan. Puisi tradisional Melayu ini berfungsi sebagai alat komunikasi utama yang digunapakai oleh nenek moyang sehingga kini. Antara puisi yang terlibat ialah seloka; fungsi asalnya dicipta untuk memberikan hiburan kepada masyarakat dengan mengangkat ikon tertentu sebagai rujukan. Kajian ini memfokus kepada peranan seloka sebagai alat komunikasi sindirian dan kritikan berkonsepkan pengajaran kepada khayalak. Antara seloka yang digunapakai sebagai rujukan ialah Seloka Pak Kaduk dan Pak Pandir. Kaedah perpustakaan dan penelitian bahan seperti artikel, buku, majalah dan tesis digunakan sebagai landasan kajian ini. Objektif kajian ialah menganalisis proses komunikasi dalam seloka. Selain itu juga kajian ini meneliti kebijaksanaan masyarakat Melayu dalam berkomunikasi. Teori yang mendasari kajian ini ialah SPEAKING framework oleh Dell Hymes. Teori ini bertujuan untuk melihat jenis sindiran yang terdapat dalam dua seloka tersebut. Hasil kajian mendapati kaedah komunikasi sindiran secara halus lembut merupakan salah satu daripada identiti masyarakat Melayu dalam menyampaikan kritikan dalam kalangan mereka. Seloka ini membawa impak yang baik kepada proses inovasi komunikasi masyarakat Melayu dalam melahirkan negara bangsa yang memiliki tingkah laku sosial yang baik.
\end{abstract}

Kata kunci: Seloka, sindiran, Pak Pandir, Pak Kaduk, SPEAKING framework.

\section{Sarcasm Language Communication in Seloka Pandir and Pak Kaduk}

\begin{abstract}
The creative work of traditional Malay poetry is recording the story of a life filled with examples. Traditional Malay poetry serves as the main communication tool used by the ancestors until now. Among the poems involved are seloka; its original function was created to provide entertainment to society by raising certain icons as references. This study focuses on the role of seloka as a tool of personal communication and criticism with the concept of teaching to the imaginary. Among the seloka used as a reference are Seloka Pak Kaduk and Pak Pandir. Library methods and research materials such as articles, books, magazines and theses are used as the basis for this study. The objective of the study is to analyze the communication process in seloka. In addition, this study examines the wisdom of the community to communicate. The theory underlying this study is the SPEAKING framework by Dell Hymes. This theory aims to look at the types of satire found in the two ditches. The findings showed that the method of communication for smooth gentle satire is one of the identities of the Malay community in disseminating criticism among them. Seloka brings a good impact on the communication innovation process in the Malay community in producing a nation that has good social behaviour.
\end{abstract}

Keywords: Seloka, sarcasm, Pak Pandir, Pak Kaduk, SPEAKING framework. 


\section{PENGENALAN}

Melayu dikenali sebagai sebuah masyarakat yang kaya dengan budi bahasa dan beradab sopan apabila berbicara. Dalam proses berkomunikasi masyarakat Melayu sangat mementingkan konsep "sebab dan akibat" bagi menjaga hubung-jalin dengan faktor sekeliling berlangsung dengan baik. Namun ada keadaan yang memerlukan mereka menegur, menasihati. Menurut Azlina et al. (2019), orang Melayu dikenali sebagai orang yang mudah berakomodasi, bertolak ansur dan mengelak berkonfrontasi dalam berhubungan sosial. Nilai dan budaya yang diwarisi orang Melayu terserlah dalam perilaku individu dan kumpulan serta perbagai perlambangan simbol kehidupan orang Melayu yang dianggap sebagai cerminan akal budi Melayu. Maka disinilah dapat dilihat kebijaksanaan masyarakat Melayu menjadikan puisi tadisional sebagai alat komunikasi menyampaikan sindiran, kritikan atau luahan.

Puisi tradisional merupakan satu genre kesusasteraan yang merupakan milik masyarakat secara bersama. Puisi tradisional ditakrifkan sebagai gambaran tentang pemikiran, falsafah, gaya hidup, gerak laku dan pelbagai lagi rencam masyarakat pengamal dan pendukungnya. Pada awalnya berfungsi sebagai pencetus semangat bagi memudahkan sesuatu urusan kerja akhirnya menjadi sebahagian kepada unsur didaktik. Puisi tradisional wujud dalam situasi kelisanan yang melahirkan pemikiran, norma dan estetika lisan yang akrab dengan kehidupan manusia. Idea yang terdapat puisi tradisional yang hadir melalui tema dan persoalan menunjukkan keakraban dengan live experience yang dilalui pengarangnya sendiri. Melalui pengalaman yang dialami atau dihayati ini maka lahirlah karya kreatif yang kaya dengan nilai alam kehidupan diterjemah dalam bentuk satu susunan kata yang perlu ditafsir. Satu daripada karya kreatif tadisional ini ialah seloka.

Harun (1989) memberikan pandangan bahawa perkataan seloka diambil dari bahasa Sanskrit iaitu Shloka; bererti sejenis puisi yang memiliki dua baris. Antara unsur yang menjadi panduan untuk mengenali seloka ialah jenaka, sindiran dan kritikan terhadap tingkah laku masyarakat ketika itu. Manakala secara fizikalnya, seloka tidak mempunyai bentuk yang tetap seperti syair dan pantun. Manakala Zaaba (1965) menyatakan seloka ialah sususan kata yang berangkap dan mempunyai perbezaan bunyi pada hujung rima. Hal ini menyokong kepada pandangan Winsted (1969):

In language abrupt and rudely phrased; it lines, rhythmical but not metrical, are padded wuth stock tags, which the reciter employed to keep the marrative marching when inspiration or memory flagged. More or less uniform in length.

Di samping itu, seloka dikarang untuk menyampaikan kritikan dan sindiran terhadap permasalahan yang terjadi dalam kelompok masyarakat. Kaedah penyampaian sindiran dan kritikan diterjemahkan dalam bentuk yang berkias ibarat. Darus (1960) berpandangan Seloka merupakan sebuah karangan puisi yang penuh sindiran atau ejekan dalam bentuk berangkap-rangkap. Justeru melalui seloka kita dapat mengenal budaya masyarakat Melayu dalam memberikan kritikan kepada masyarakat tanpa mengguriskan hati mana-mana pihak. Seloka juga merupakan penyatuan isi atau idea yang lengkap.

Seloka adalah sejenis puisi yang biasanya terdiri daripada dua, empat atau lebih baris. Seloka disusun dengan cara yang menarik tetapi setiap fungsi tidak tetap nombornya. Oleh itu, seloka tidak sama dengan irama akhirnya dan bebas berirama. Seloka kandungan biasanya terdiri daripada lelucon dan mesej sindiran tajam. Selain itu, seloka juga dijadikan 
panduan dalam perbandingan dan simulasi seperti imejan, kiasan, keperibadian dan simile yang penuh dan kaya dengan unsur dan gambar semula jadi. Terdapat tujuh jenis seloka yang terdapat di dalam kumpulan seloka yang tergolong dalam masyarakat Melayu. Antaranya adalah satira seloka, seloka ejekan, seloka mengejar, nasihat, pengajaran pengajaran, seloka fantasi dan jenaka.

Fungsi yang jelas seloka untuk memberi kritikan dan satira terhadap isu yang berlaku dalam sebuah masyarakat. Semua kritikan dan sindiran yang diberikan dijelaskan untuk mengelakkan perasaan tersinggung oleh individu bertujuan untuk sindiran dan kritikan seperti itu. Selain itu juga satira dalam seloka boleh menjadi jenaka atau serius dan mungkin mengandungi elemen yang lain seperti keseronokan, ketenangan, fantasi dan impian. Dalam isi seloka juga sering berkaitan dengan cerita rakyat yang biasanya dikenali sebagai Pak Kaduk, Lebai Malang, Nujum Pak Belalang dan lain-lain. Di samping itu, penciptaan seloka ini telah menjadi bukti nilai yang wujud dalam masyarakat Melayu, iaitu nilai kesopanan. Ini kerana penciptaan seloka sebagai medium untuk menyampaikan rasa tidak puas hati terhadap sesuatu yang menggambarkan sikap masyarakat Melayu yang mengambil berat keharmonian dan ketidakcekapan kritikan dan pendapat. Rentetan itu secara keseluruhan, sekuel itu merujuk kepada kisah jenaka yang pernah terkenal dalam masyarakat seperti kisah Pak Kaduk, Pak Pandir, Lebai Malang dan kisah Emak Si Randang. Tujuannya adalah untuk melepaskan perasaan yang berperang masyarakat seperti tokoh-tokoh itu. Seloka biasanya mengandungi bahasa yang ceritanya berpusing dan bergerak, bersungguh-sungguh menyindir dan selalu tajam serta boleh seperti mengejek dan mengandungi perasaan rendah diri.

\section{SOROTAN KARYA}

Seloka merupakan karya sastera puisi tradisional Melayu yang sarat dengan bingkisan pengajaran, nasihat dan teguran kepada seseorang. Pengungkapan seloka dizahirkan secara turun temurun daripada generasi yang menurunkannya sehingga diresap generasi yang menerimanya sebagai manfaat untuk kehidupan. Nordiana (2019), meneliti siri kajian seloka yang terdiri daripada seloka Pak Pandir, Pak Kaduk, Emak Si Randang, Si Luncai dan Mat Jenin dengan mengungkapkan watak dalam Seloka Melayu sebagai ikon teladan yang memberikan imej baik kepada khalayak. Selain itu, kajian tersebut juga mendapati setiap ikon dalam seloka membawa impak yang positif kepada penciptaan jati diri dan tingkah laku sosial di samping garapan watak yang mencerminkan sudut pandangan yang baik kepada khalayak. Sesuatu yang lebih menarik, seloka mempunyai hubungan erat dengan peribahasa dan cerita jenaka. Hubungan itu timbul menerusi isi dan tema seloka yang memperkatakan tentang cerita jenaka Melayu terkenal seperti Pak Pandir dan Pak Kaduk yang sering dijadikan dasar kias ibarat. Sindiran berbentuk ejekan menerusi seloka tersebut dianggap sebagai manifestasi kritikan negatif terhadap sikap jelek manusia yang bertujuan memberi kesedaran kepada mereka (Shaiful Bahri, 2005).

Siti Norsyahida dan Nor Azuwan (2017) dalam artikel bertajuk 'Jenis Bahasa Sindiran dalam Ujaran Vlog' telah menjalankan penganalisisan dengan meneliti elemen bahasa sindiran yang terdapat dalam ujaran vlog dari ikon media sosial iaitu Mat Luthfi. Hasil kajian memperlihatkan ungkapan dialog yang dizahirkan oleh vlogger terkemuka tersebut mengandungi unsur humor yang memberi kejutan tatkala ia disampaikan. Penyampaian bahasa sindiran secara ironi, sarkastik dan sinisme itu merupakan satu bentuk kata tersirat yang menyukarkan penginterpretasian makna sesuatu ujaran. Kajian tersebut juga 
memperlihatkan proses komunikasi secara sindiran masih disadurkan masyarakat dalam abad ke-21 ini. Begitu juga kajian yang dilakukan oleh Mokodongan (2015) meneliti jenis dan gaya bahasa sindiran dalam sebuah rancangan Sentilan Sentilun di Metro TV. Hasil penelitian tersebut menemui beberapa jenis gaya bahasa sindiran seperti satira, sarkasme, sinisme, dan innuendo yang diguna pakai dalam rancangan tersebut. Selain itu, kajian tersebut turut memperlihatkan makna seperti ideasional, kognitif, konotatif, konstruktif, dan emotif dalam beberapa gaya bahasa sindiran yang dikaji. Kajian gaya bahasa sindiran yang berunsur ironi, innuendo, sarkasme, satira dan sinisme turut dijalankan oleh beberapa penyelidik lain seperti Halimah dan Hilaliyah (2019), Prameswari. (2019), Rahmat dan Rajab (2019) serta Wahyuni (2018).

Selain daripada itu, Nor Hasimah, Melor Fauzita, Nazilah dan Julizayati (2017) yang bertajuk "The Human Capital in Seloka Pak Kaduk" menerangkan bahawa seloka adalah sebuah puisi tradisional Melayu yang merupakan suatu kesatuan kandungan dan idea yang lengkap dalam mengandungi pengajaran-pengajaran seperti sindiran dan nasihat. Dari segi bentuk, seloka terbahagi kepada dua atau empat baris. Kandungan dalam seloka kebiasaannya terdiri daripada mesej yang halus dan tajam. Pengkaji menambah, modal insan boleh dikembangkan kepada tiga aspek utama seperti watak yang baik, prinsip dan falsafah yang kuat serta berintegriti iaitu berwawasan. Pembangunan modal insan mestilah diberi tumpuan. Hal ini demikian kerana, modal insan yang berkualiti merupakan elemen penting dalam mencapai kehidupan yang holistik. Pengkaji turut menyatakan nilai yang terdapat dalam seloka Pak Kaduk yang dapat membantu membina hati serta aspek luaran dan dalaman seseorang. Modal insan yang diperoleh mampu melahirkan seseorang yang berfikiran secara rasional, kreatif dan kritis.

Kajian Micheals (dalam Mukhlis, 2008) yang menganalisis cara bertutur kanak-kanak yang membantu mereka dalam memahami penggunaan bahasa di sekolah. Responden terdiri daripada kanak-kanak yang mengambil giliran untuk menerangkan sesuatu objek atau menceritakan sesuatu peristiwa kepada rakan-rakan di dalam kelas. Guru pula akan menyoal dan memberi komen, supaya kanak-kanak ini tertumpu pada satu-satu perkara dan menstrukturkan wacana mereka agar penerangan dan penceritaan menjadi lebih eksplisit dan tidak bergantung pada pengetahuan latar yang tidak mungkin diketahui oleh pendengar.

Susan U. Philips (1972) pula mengkaji percakapan kanak-kanak penduduk asli Amerika di sebuah sekolah di Central Oregon. Beliau memerhati percakapan kanak-kanak tersebut dan mendapati mereka hanya bercakap dan mahu bercakap pada masa-masa tertentu sahaja di dalam kelas. Kanak-kanak ini enggan bercakap disebabkan mereka menggunakan bentuk-bentuk percakapan yang lain jika dibandingkan dengan bahasa yang digunakan di sekolah. Masyarakat peribumi belajar dengan melihat dan mendengar secara senyap, dan melatih kemahiran diri secara tertutup sebelum menunjukkannya di hadapan khalayak. Oleh itu, kanak-kanak ini berasa tidak selesa apabila guru menyoal mereka di dalam kelas kerana perasaan rendah diri akan menguasai apabila mereka melakukan kesilapan di hadapan khalayak.

Selain itu, terdapat juga kajian yang dijalankan oleh Ghazali dan Shamsudin (2016) yang bertajuk 'Tinjauan Interaksi Lisan Bahasa Melayu dalam Kalangan Remaja Malaysia dari Sudut Etnografi Komunikasi.' Kajian ini memfokus aliran bahasa yang dituturkan oleh remaja dalam komunikasi lisan serta menilai kebolehan berbahasa di empat buah sekolah menengah di daerah Kuala Langat, Selangor. Di samping itu, kajian ini juga membincangkan aspek kognitif yang mempengaruhi interaksi lisan dalam kalangan remaja. Kajian ini telah 
membuktikan terdapat kecekapan berbahasa dalam kalangan remaja yang menyertai proses interaksi lisan dalam situasi formal (Ghazali \& Shamsudin, 2016, hlm. 39).

Selain itu, "Keintelektualan Pemikiran Melayu dalam Cerita Lipur Lara: Penelitian Awal Berdasarkan Perspektif Pendekatan Pengurusan" oleh Mohamad Zuber dan rakanrakannya (2015) menyatakan bahawa dalam cerita Hikayat Awang Sulung Merah Muda terdapat unsur pengurusan dengan mengaplikasikan Pendekatan Pengurusan iaitu sebagai pendekatan yang baharu dalam dunia kritikan sastera di Malaysia. Pengkaji menambah bahawa kajiannya menggunakan Prinsip Kepimpinan iaitu salah satu prinsip yang diketengahkan dalam Pendekatan Pengurusan oleh Mohamad Mokhtar Abu Hassan (2013). Seterusnya, pengkaji menyatakan paparan dalam tradisi keilmuan jelas memperlihatkan kepada kreatif minda dan intelektual pemikiran masyarakat Melayu tradisi dalam sastera lisan sebagai khazanah warisan yang unggul dan agung. Keintelektualan pemikiran keilmuan yang dipaparkan dalam teks kajian amat signifikan dan relevan dalam memperjelaskan kebijaksanaan dan ketajaman imaginasi dan sensitiviti pengarang khususnya melibatkan aspek kepimpinan.

Kajian seterusnya bertajuk "Meme Sebagai Seloka Persendaan dan Parodi: Impak Dimensi Sosiobudaya" oleh Faizul Nizar, Fauziah dan Sabariah (2018) menyatakan dengan jelas dalam kajiannya bahawa perkongsian maklumat menerusi Internet bukanlah suatu perkara yang baru dalam kalangan masyarakat. Pengkaji menambah, keadaan ini dirancakkan lagi dengan kehadiran pelbagai media teknologi dan komunikasi sebagai alat berkomunikasi dan menyampaikan sesuatu maklumat. Selain itu, kandungan meme dilihat sebagai satu medium penyampaian maklumat mengenai suatu isu hangat ataupun kontroversi. Ada di antaranya sengaja dihasilkan sebagai mempersendakan seseorang menerusi peniruan sesuatu perkara contohnya dalam bentuk gambar atau video parodi. Pengkaji berkata, keadaan ini mampu memberikan kesan kepada individu yang menerima meme berkenaan. Oleh itu, kajian pengkaji ini dijalankan untuk mengenal pasti impak kepada penghasilan meme berkenaan dalam kehidupan sosiobudaya di Malaysia.

Md. Sabri (2004) dalam 'Wacana Wawancara Formal Bahasa Melayu: Satu Kajian Etnografi Komunikasi' telah mengkaji sepuluh teks wawancara formal yang melibatkan sepuluh tokoh tempatan dalam pelbagai bidang dengan menggunakan model grid speaking yang dipelopori oleh Hymes (1972) dan diaplikasikan oleh tokoh-tokoh bahasa seperti Muriel Saville-Troike (1989), Ralph Fasold (1990), Deborah Schiffrin (1994) dan Asmah Hj. Omar (1997). Dapatan kajian ini mendapati bahawa teori tersebut mampu membina satu sistem keteraturan dalam pertuturan dan berjaya menjelaskan fungsi dan hakikat bahasa sebagai sebahagian daripada falsafah dan pemikiran bahasa.

\section{METODOLOGI KAJIAN}

Kajian ini menggunakan pendekatan kualitatif. Bahan premier dan sekunder dijadikan sebagai bahan untuk analisis kajian. Antara kaedah kajian yang digunakan ialah kajian perpustakaan dengan merujuk dan menganalisis bahan bacaan seperti buku, tesis, artikel jurnal, makalah dan lain-lain lagi. Bagi meneliti senario sindiran halus yang terjadi dalam dunia alam Melayu, satu pemerhatian dilaksanakan terhadap kajian lalu berkenaan seloka. Kajian ini menggunakan pendekatan kualitatif dengan kaedah tekstual teks. Kaedah ini digunakan bagi tujuan mengumpul maklumat berkaitan bahasa sindiran lembut halus melalui ujaran yang disampaikan dalam seloka terpilih iaitu Seloka Pak Pandir dan Pak Kaduk. Elemen laras bahasa menjadi penerokaan utama bagi mengesan unsur-unsur 
sindiran yang disampaikan secara implisit melalui beberapa teknik seperti Kaedah Penyampaian (Instrumentalities), Peristiwa (Norms of Interaction) dan Jenis peristiwa berbahasa (Genre) menerusi Kerangka SPEAKING framework oleh Dell Hymes. Gaya pertuturan dalam seloka juga dilandaskan kepada empat jenis gaya bahasa yang utama iaitu, gaya bahasa perulangan, gaya bahasa pertentangan, gaya bahasa pertautan dan gaya bahasa perbandingan (Henry Guntur Tarigan, 1985). Metodologi yang digunakan ini dilihat mampu mencerminkan perkembangan aktiviti kajian berkenaan sindirin halus yang berfokus kepada seloka serta memperlihatkan kepelbagaian rentak penyampaian sindiran yang diaplikasi menerusi khazanah puisi tradisional Melayu ini. Pendekatan ini digunakan bagi mencapai objektif dan dapat menjelaskan permasalahan yang ingin diketengahkan. Berikut berdasarkan Model "Hymes".

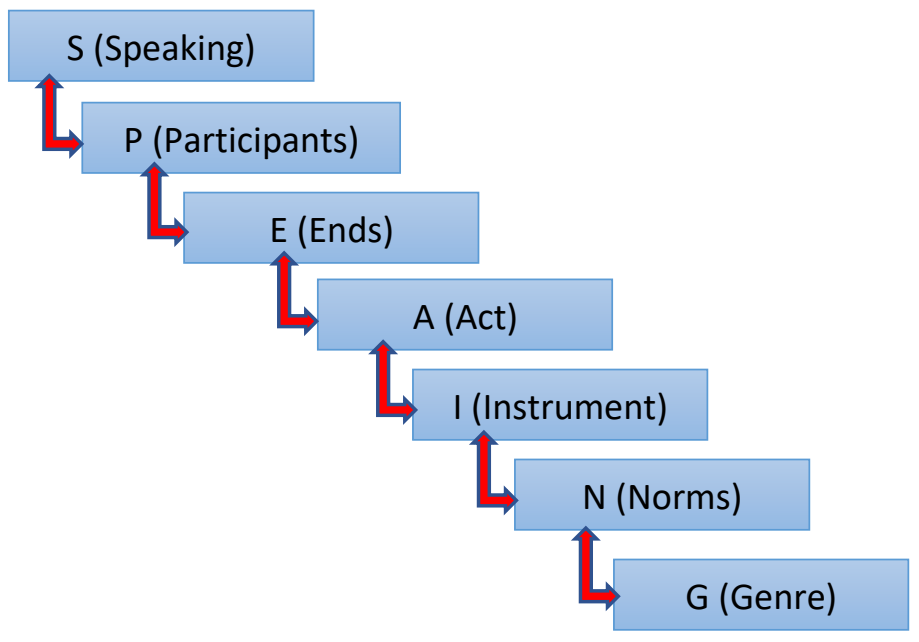

Rajah 1: Etnografi Pertuturan SPEAKING framework

\section{PERBINCANGAN}

Analisis perbincangan memfokus kepada dua seloka iaitu Seloka Pak Kaduk dan Pak Pandir. Bersandarkan kepada unit-unit analisis etnografi komunikasi, model yang diakronimkan dalam kata SPEAKING (Kiki Zakiah Darmawan, 2008) dikembangkan oleh Dell Hymes. Hymes (dalam Darmawan, 2008) memperkenalkan satu kerangka dimensi peristiwa komunikasi yang disebut SPEAKING framework. Setiap unit komunikasi dijelaskan dengan bantuan sistem penggolongan atau grid perbualan SPEAKING framework, iaitu setiap huruf merupakan singkatan bagi setiap komponen berbeza yang berperanan dalam sesuatu komunikasi. Terdapat lapan unit analisis etnografi komunikasi ini namun hanya tiga unit sahaja yang digunakan dalam mengukur sindiran halus lembut dalam seloka iaitu Instrumentalities (I), Norms of Interaction (N) dan Genre (G)

\section{SINDIRAN DALAM TINGKAHLAKU}

Penggunaan bahasa dalam seloka selalunya mempunyai ciri konotasi iaitu merujuk kepada bahasa yang digunakan mempunyai makna lebih dari satu. Hal ini memerlukan ketajaman pemikiran dan emosi khalayak untuk memahami maksud yang cuba disampaikan. Melalui Model Pertuturan Dell Hymes, perbuatan atau tingkahlaku Pak Pandir dalam seloka merupakan satu sindiran masyarakat Melayu ketika itu. Seloka Pak Pandir ini dibahagikan kepada lima peristiwa seperti berikut: 


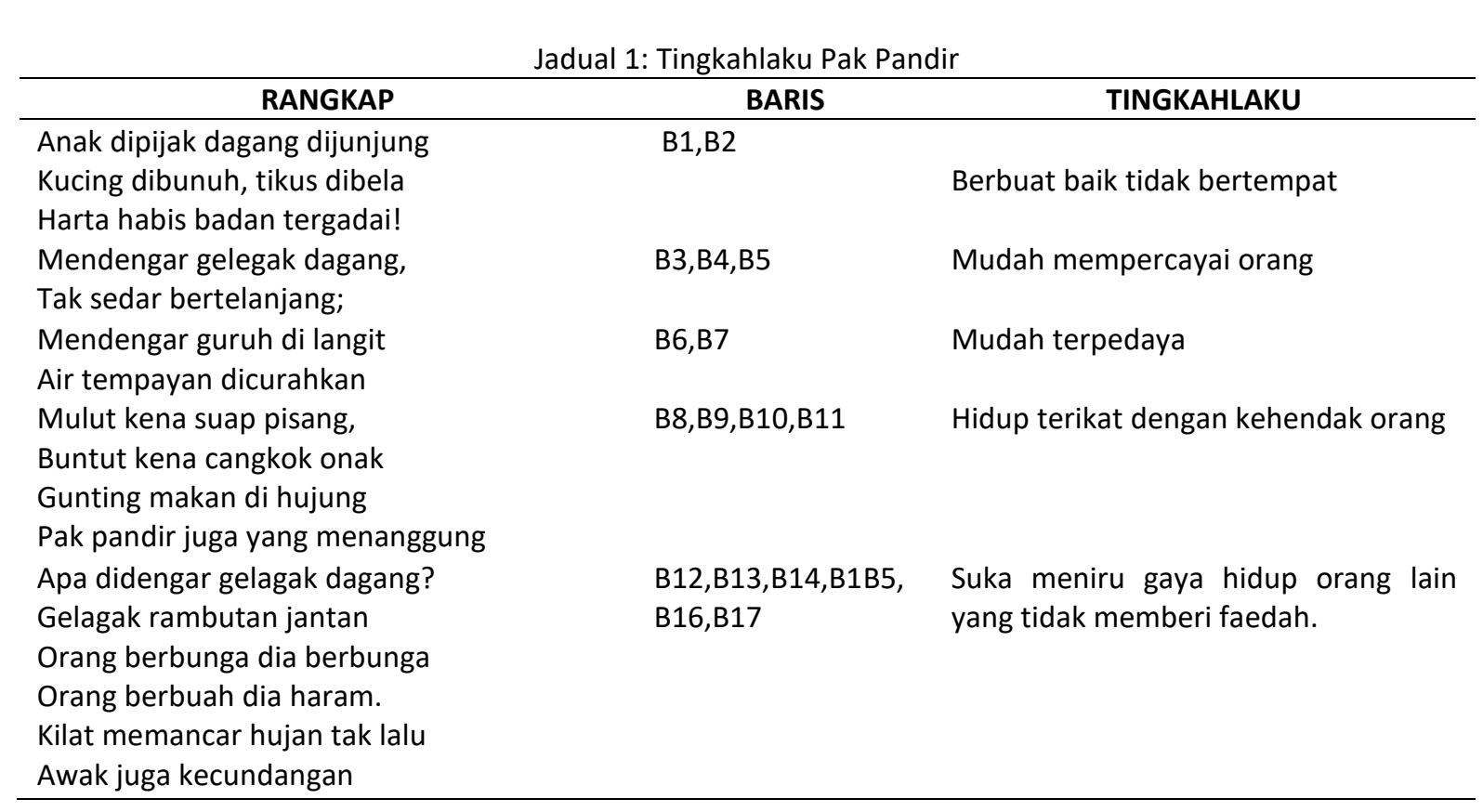

\section{BERBUAT BAIK TIDAK BERTEMPAT}

Dalam seloka Pak Pandir jelas berlakunya kritikan kepada sikap beliau yang suka melakukan kebaikan tetapi tidak pada waktu, tempat dan orang yang sesuai. Selari dengan fungsi Seloka bertujuan untuk memberikan sindiran dan kritikan, B1-B2 menunjukkan sikap kelakuan Pak Pandir yang menjadi topik perbincangan ini. Hal ini diterjemahkan dalam petikan seloka di bawah:

\section{Anak dipijak, dagang dijinjing \\ Kucing dibunuh, tikus dibela \\ (Seloka Pak Pandir, Himpunan Puisi Klasik, hlm. 60)}

Analogi yang cuba disampaikan dalam seloka di atas ialah gambaran watak Pak Pandir yang memelihara tikus; binatang yang menjadi ancaman dalam rumah manakala kucing yang berperanan sebagai binatang peliharaan dibunuh. Melalui seloka ini juga, jati diri pengarang juga dapat dilihat melalui kepengarangan dalam menghasilkan karya seloka Melayu tersebut yang mempunyai nilai dan ciri-ciri keunggulan dalam karya yang telah dihasilkan oleh pengarang. Hal ini dapat dibuktikan dengan cara penulisan yang digunakan oleh pengarang yang mempunyai sifat-sifat berani dan bijak dalam berkarya kreatif. Hal ini selari dengan pandangan Affandi (1992) dan Braginsky (1993) dalam Fadzilah Amzah (2016) yang menyatakan bahawa karya sastera yang baik mampu membawa khayalak dekat dengan penciptaNYA. Selain itu juga dalam B1-B2 ini memberikan penekanan melalui model SPEAKING secara Penyampaian (Instrumentalities) menunjukkan bahawa kejelasan fungsi seloka untuk memberikan sindirian.

\section{Mudah Terpedaya}

Watak Pak Pandir dalam seloka hadir sebagai satu unsur didaktik dalam mendidik masyarakat. Hal ini bertepatan dengan tujuan pengarang menghasilkan seloka bertujuan sebagai pengajaran kepada masyarakat. Dalam petikan seloka di bawah perbuatan Pak Pandir selalunya akan mendatangkan kerugian kepada kehidupan beliau. Penggunaan 
peribahasa dalam seloka ini memberikan sindiran secara halus yang memerlukan khalayak menakluk dengan akal budi bagi memahami.

Mendengar guruh dilangit

Air tempayan dicurahkan.

(Seloka Pak Pandir, Himpunan Puisi Klasik, hlm. 61)

Dalam B1 di atas "Mendengar guruh dilangit" membawa kepada peristiwa Pak Pandir yang tamak haloba dek kerana percaya bunyi guruh tersebut akan mendatangkan hujan yang banyak. Lalu berlaku peristiwa B2 "Air tempayan dicurahkan" yang akhirnya mendatangkan kerugian kepada dirinya.

\title{
Mudah Mempercayai Orang Asing
}

Watak Pak Pandir digambarkan sebagai seorang yang lebih mengutamakan orang luar berbanding keluarga sendiri. Kepercayaan Pak Pandir kepada orang luar dari keluarganya sangat tinggi. Hal ini memberikan persepsi bahawa watak Pak Pandir memiliki karakter yang tidak yakin kepada diri sendiri dan menyerahkan sebulat-bulatnya urusan diri sendiri kepada orang yang tidak dikenali. Hal ini dirakam dengan jelas dalam petikan seloka di bawah:

\author{
Kucing dibunuh, tikus dibela \\ Harta habis, badan tergadai \\ Mendegar gelakak dagang \\ Tak sedar bertelanjang. \\ (Seloka Pak Pandir, Himpunan Puisi Klasik, hlm. 61)
}

Dalam petikan di atas memerlukan ketajaman akan fikiran untuk memberikan tafsiran tentang karakter Pak Pandir. Norma masyarakat Melayu yang suka medahulukan orang lain diperkatakan oleh Noriati (2005), Orang Melayu mempunyai satu sikap mengutamakan perasaan orang lain berbanding diri sendiri dalam apa sahaja situasi yang memerlukan pertimbangan untuk membuat keputusan. Ting Toomey (1988) menjelaskan pula sikap tersebut sebagai "other-concern positive face". Justeru dalam analisis ini sebagai individu yang hidup dalam kelompok bermasyarakat, perlu bijak membezakan kepentingan antara diri, keluarga dan masyarakat. Sikap mudah mempercayai orang asing ini boleh memakan diri sendiri. Perlu ada komunikasi antara setiap individu supaya kesepakatan dapat dicapai bersama dan boleh mengelakkan berlakunya pertentangan dari aspek tujuan peribadi.

\section{SINDIRAN MELALUI GAYA BAHASA}

Berdasarkan Model Etnografi Pertuturan SPEAKING Framework oleh Dell Hymes (1967) elemen (instrumentalities) merupakan kaedah penyampaian secara verbal atau bertulis. Penelitian tersebut diukur melalui kod (codes) yang digunakan seperti variasi, cara pemakaian bahasa dan gaya bahasa pertuturan. Gaya bahasa dapat dikategorikan dalam pelbagai cara dan kebiasaannya ia bergantung kepada identiti seseorang penulis dalam menghasilkan sesebuah karya. Pengungkapan gaya bahasa digunakan bagi meningkatkan kesan dengan memperkenal dan membandingkan suatu benda atau hal tertentu dengan perkara yang lain secara umum. Menurut Dale Spender (1980), penggunaan gaya bahasa tertentu dapat mengubah serta menimbulkan kesan konotasi (Tarigan, 1985). Bahasa 
sindiran merupakan salah satu teknik penyampaian yang menjadi dukungan dalam menerbitkan karya berunsur humor. la diterjemahkan sebagai satu gaya bahasa yang bertentangan dengan maksud tersurat. Tujuan penyampaiannya adalah untuk menyindir seseorang secara halus. Di samping itu kajian berbentuk ujaran atau penyampaian tidak hanya tertumpu melalui dialog semata-mata, namun dalam masa yang sama memperagakan hubungan sosial antara watak yang dinamik melalui ujaran yang disampaikan (Mohammad Fadzeli, 2016). Tarigan (1985) mengklasifikasikan elemen bahasa sindiran kepada beberapa jenis iaitu sarkasme, sinisme, satira, ironi, dan innuendo. Berdasarkan penerokaan terhadap Seloka Pak Kaduk, dikesani banyak menampilkan elemen gaya bahasa sindiran seperti yang digariskan dalam pernyataan Tarigan.

Jadual 2: Elemen Gaya Bahasa Sindiran Dalam Seloka Pak Kadok

\begin{tabular}{lcc}
\hline \multicolumn{1}{c}{ RANGKAP } & BARIS & GAYA BAHASA \\
\hline $\begin{array}{l}\text { Mudik menongkah surut } \\
\text { Hilir menongkah pasang }\end{array}$ & B5, B6, B10 & Satira \\
$\begin{array}{l}\text { Sauh dilabuh bayu berpuput } \\
\text { Ayamnya menang kampung tergadai }\end{array}$ & & \\
$\begin{array}{l}\text { Awak pulang kebuluran } \\
\text { Ada isteri dibunuh }\end{array}$ & B2, B4, B7 & Innuendo \\
$\begin{array}{l}\text { Ada nasi dicurahkan } \\
\text { Nyaris mati oleh tak makan }\end{array}$ & B3, B8 & Sinisme \\
\hline
\end{tabular}

\section{Satira}

Satira merupakan penggunaan humor secara luas untuk tujuan mentertawakan atau menolak sesuatu masalah. Namun mentertawakan masalah itu menekankan terhadap ejekan, kritikan moral, sosial mahupun politik. Satira juga mengandungi kritikan tentang kelemahan manusia dengan tujuan memberi kesedaran dan menambaik dari kelemahan yang ada (Keraf, 1985). Bahasa sindiran jenis satira juga merupakan sejenis bentuk ujaran yang disampaikan secara tidak langsung, malah kadang kala disampaikan secara aneh melalui elemen komedi bagi menimbulkan kelucuan. Dalam bidang linguistik, ujaran berkaitan perbualan telah lama dikaji oleh ahli pragmatik. berdasarkan wacana lisan. Sebaliknya, kajian tentang wacana tulisan lebih banyak diterokai oleh ahli stilistik kerana bidang stilistik lebih memberi perhatian pada teks kesusasteraan, misalnya puisi, drama dan novel (Mohammad Fadzeli, 2016). Menurut Tarigan (1985), satira ditanggapi sebagai bahasa serangan berkonsepkan lucu yang mengharapkan ia ditertawakan tatkala disampaikan kepada seseorang. Namun setiap pernyataan yang dihujahkan itu sebenarnya mengandungi unsur tersirat bagi memberi kesedaran dan mengajak seseorang berfikir tentang sesuatu yang disampaikan kepada mereka. Mendepani Seloka Pak Kaduk yang sangat sinonim dalam dunia penceritaan puisi tradisional Melayu, ia mengisahkan seorang figura yang sering bertindak tanpa memikirkan rasional sehingga mendatangkan musibah malang terhadap dirinya. Tumpuan terhadap Seloka Pak Kaduk dikesani terdapat beberapa baris ujaran menggambarkan elemen satira yang mengandungi nilai kelucuan. Namun, konteks kelucuan itu bukanlah cerminan utama wadah penyampaiannya, tetapi ia memberi gambaran tentang nilai kedangkalan akal fikiran yang mendatangkan musibah dan bahana atas perbuatan tersebut. Teks ujuaran seperti berikut: 
Mudik menongkah surut,

Hilir menongkah pasang,

Sauh dilabuh bayu berpuput,

(Sahlan Mohd. Saman, 2005, hlm. 45)

Berdasarkan teks 'mudik menongkah surut' | 'Hilir menongkah Pasang' merupakan sesuatu perkara yang bertentangan dilakukan dalam dunia pelayaran. Tindakan Pak Kaduk bermudik dalam arus air bertentangan itu mendatangkan kepenatan yang akhirnya mendatangkan kerugian kepadanya. Perkara ini jelas mencerminkan Pak Kaduk ialah seorang yang tidak menggunakan akal budi ketika melakukan sesuatu dan membuktikan bahawa Pak Kaduk merupakan orang yang lurus dan dungu. Meskipun tindakan yang dilakukan itu mencerminkan kelucuan, namun dalam ujaran tersebut menggambarkan sindiran satira yang mempunyai makna tersirat. la bertepatan dengan penjelasan satira sebagai satu bentuk humor tinggi yang merangkumi mesej eksplisit dan implisit yang menyumbang kepada konsep ideologi dan propaganda (Athirah, 2015). Justeru itu, makna sebenar di sebalik ujaran tersebut adalah ingin menyatakan kepada khalayak bahawa jika melakukan sesuatu perkara tanpa menggunakan akal yang rasional, akan mendatangkan perkara yang sia-sia. Aplikasi tersebut merupakan bentuk nasihat melalui penyampaian bahasa halus yang memberi dedikasi supaya melakukan sesuatu perkara menggunakan akal dan berhati-hati agar tidak mengundang musibah kepada diri sendiri. Pengungkapan secara halus atau sindiran ini bertepatan dengan pandangan Zainal Abidin Ahmad (Za'ba) (2002), bahawa bahasa melalui kiasan langsung dan tidak langsung merupakan ungkapan bersopan yang melengkapi ketinggian adab dan kesopanan orang Melayu dari sudut nilai, budaya, pemikiran dan falsafah (Noor Hasnoor, Eizah \& Ahmad Ramizu, 2019).

Begitu juga pada ujaran teks 'Sauh dilabuh bayu berpuput' yang menjelaskan elemen satira dengan tindakan Pak Kaduk melabuhkan sauhnya ketika angin sedang bertiup. Menerusi ilmu perkapalan tradisional, sesebuah kapal atau perahu digerakkan melalui pergantungan kepada unsur angin yang bertiup mengikut arah dan waktunya. Namun, sindiran satira jelas terpamer dari tindakan Pak Kaduk yang melabuhkan sauhnya tatkala angin mula bertiup. Perkara tersebut sememangnya bertentangan dari tindakan seseorang kelasi atau pengemudi kapal. Ujaran tersebut bersifat halus tetapi mempunyai makna implisit di sebaliknya kerana ia menyampaikan mesej agar sentiasa menggunakan kewarasan berfikir dalam setiap tindakan. Kelemahan membuat keputusan dan tidak menggunakan pertimbangan akal yang waras akan mendatangkan kerugian. Malah, kebodohan disebabkan oleh sikap terburu-buru, tidak rasional, tidak berfikiran terbuka, tidak mempunyai kemahiran dan ilmu, dan bertindak mengikut emosi boleh merugikan diri sendiri serta masyarakat. Satira sememangnya unsur ujaran yang menampilkan elemen kelucuan dalam penyampaiannya, maka penafsiran sebenarnya memerlukan daya fikir yang mendalam serta menghayati implikasi yang terkandung secara tersirat dalam setiap baris ujaran yang disampaikan. Hal ini bertepatan dengan pandangan Siti Norsyahida dan Nor Azuwan (2017) yang menyatakan penggunaan kata tersirat akan mendatangkan kesan sama ada positif atau negatif terhadap penerima dan bergantung kepada penerimaan seseorang.

\section{Innuendo}

Bahasa merupakan satu komunikasi yang digunakan bagi mengungkapkan sesuatu hal sama ada secara lisan mahupun tulisan. Kepelbagaian gaya bahasa yang ditampilkan pengarang akan menambahkan nilai estetika terhadap karyanya sehingga mampu menarik minat 
pembaca. Innuendo merupakan salah satu gaya bahasa yang muncul dalam kategori gaya bahasa pertentangan yang berbentuk sindiran dengan mengecilkan fakta dan kenyataan yang sebenarnya (Tarigan, 1985, Siti Komariya, 2015). Sedangkan Keraf (2007), menyatakan innuendo sebagai gaya bahasa sindiran dengan pernyataan yang tidak langsung dan berkemungkinan tidak menyentuh perasaan jika difahami secara tersurat. Sebagai contoh petikan berikut:

\section{Ayamnya menang kampung tergadai \\ Awak pulang kebuluran \\ Ada isteri dibunuh}

(Sahlan Mohd. Saman, 2005, hlm. 45)

Merujuk beberapa contoh dari ujaran tersebut, menjelaskan pernyataan secara eksplisit berkenaan perbuatan Pak Kaduk yang bertindak tanpa memikirkan kesannya. Pada baris 'Ayamnya menang kampung tergadai' membawa maksud perbuatan Pak Kaduk yang menerima pelawaan raja untuk menukar ayam jantannya yang bertuah dengan ayam jantan baginda. Pada hemah Pak Kaduk, ayam jantan tersebut sudah pastinya mempunyai tuah tertentu kerana ia milik dari raja yang terpelihara dengan baik. Pak Kaduk tanpa memikirkan kesannya terus bersetuju dengan pelawaan tersebut dan menyahut seruan raja untuk bertanding sabung ayam dengan mencagarkan kampungnya kerana dia tidak mempunyai harta dan wang. Malang menimpa Pak Kaduk, ayam daripada raja yang diharapkan mendatangkan tuah, akhirnya mati tertusuk tajinya sendiri ketika berlawan. Kemenangan itu dicapai oleh raja daripada ayam Pak Kaduk yang telah ditukarkan dan kampungnya juga tergadai kepada raja. Gaya bahasa innuedo dikesani dari aspek siratan makna yang dihujahkan menerusi ujaran tersebut. Meskipun secara umumnya, penjelasan tersebut tidak menempelkan sisi persepsi yang ganjil, namun di sebalik kisah yang terjadi dari sikap kedunguan Pak Kaduk, telah membinasakan kehidupan masa depan dan kampungnya.

Ujaran 'Awak pulang kebuluran' | 'Ada isteri dibunuh', juga merupakan kiasan tersirat dari elemen gaya bahasa innuendo. Permukaan makna lapis pertama tidak menampakkan kecanggungan kefahamannya kerana ia disampaikan secara langsung dan mudah difahami tanpa memikirkan persepsi di sebaliknya. Menerusi penceritaan sebenar, Pak Kaduk pulang dalam keadaan hampa dan kelaparan sedangkan dia menghadiri dua kenduri yang dipelawa penduduk kampung hulu dan hilir. Namun, ketika dalam perjalanan menuju ke kedua-dua buah kenduri tersebut, nasib malang terjadi kepadanya. Insiden ini berlaku apabila Pak Kaduk mahu belayar ke hulu tetapi dia mengikut arus air pasang surut. Tindakan itu membawa Pak Kaduk mengambil masa yang lama untuk sampai ke lokasi tersebut sehingga kenduri itu sudah berakhir. Pak Kaduk pulang ke rumah dalam keadaan hampa dan lapar. Malah, dia berasa berang tatkala ditanya isterinya tentang juadah makanan kenduri yang dihadiri. Pak Kaduk sukar mengawal emosi dan nafsu lalu membunuh isterinya dengan mengetuk kepala menggunakan tunggul kayu. Di sini, sindiran innuedo yang boleh digambarkan adalah sikap Pak Kaduk yang tamak dan tidak menggunakan akal fikiran yang waras dalam sebarang tindakan. Sikap panas baran dan bengis Pak Kaduk juga telah menyebabkan dia kehilangan isterinya. Jelas fakta tersurat yang disampaikan melalui ujaran tersebut berbeza jika diperincikan melalui kesan sindiran dari gaya bahasa innuendo. Ujaran ini dikatakan sebagai sindiran kerana mempunyai makna implisit bagi tujuan menyedarkan perbuatan seseorang yang dianggap tidak baik. la bertepatan dengan 
Innuendo yang merupakan perbuatan mencemuh atau menyindir seseorang secara halus dan tajam agar tidak bertindak secara melulu. Sememangnya, cara penyampaian yang bersahaja dengan menyelitkan unsur seloka menjadikan kandungan maklumat itu berbeza dengan kandungan maklumat yang lain. Perkara ini sememangnya mampu meninggalkan kesan terhadap individu yang menerima ujaran tersebut (Faizul, Fauziah \& Sabariah, 2018).

\section{Sinisme}

Sinisme merupakan jenis gaya bahasa sindiran berbentuk kesangsian yang mengandungi ejekan terhadap keikhlasan dan ketulusan hati seseorang (Henry Guntur Tarigan, 1985). Pandangan Siti Norsyahida dan Nor Azuwan (2017) pula menyatakan sinisme sebagai gaya bahasa sindiran dengan cara pengungkapan yang lebih kasar berbanding ironi, malah juga dikaitkan dengan unsur mengejek dan menyindir. Menurut Faizul Nizar, Fauziah dan Sabariah (2018), terdapat peniruan yang dilakukan secara sengaja bertujuan untuk mempermainkan seseorang. Begitu juga pada kenyataan Arba'ie Sujud, (2010) memperihalkan sinisme sebagai sindiran yang mengandungi makna yang terselindung dan bersifat sinis. Penelitian terhadap ujaran pada baris 'Ada nasi dicurahkan' | 'Nyaris mati oleh tak makan' merupakan bauran sinis kata yang memperli tindak tanduk dari perbuatan yang mendatangkan kerugian. Menerusi konteks ujaran tersebut, ia menyindir sikap seseorang yang tamak dan tidak bersyukur dengan segala nikmat yang diberikan. Perkara ini pasti difahami sekiranya pembaca berada dalam konteks situasi yang sama dalam pengujaran tersebut, iaitu orang yang tamak selalunya mendatang musibah kerugian kepadanya. Perasaan tamak ini wujud dari rasa yang tidak pernah cukup dengan kekayaan harta benda yang dimiliki. Hal ini selari dengan pendapat Kamarudin Arim (2004) di mana faktor berlakunya kes rasuah kerana rasa tamak dan ketidapuashatian harta yang dimiliki (Enida Daud, 2019).

Dalam Seloka Pak Kaduk, nilai ini dapat dipersoalkan dan dilihat melalui perlakuan Pak Kaduk. Pak Kaduk semestinya berfikir secara wajar dan bertindak secara rasional. Namun, apa yang berlaku adalah sebaliknya kerana dia tidak berfikir Panjang. Ini kerana Pak Kaduk sanggup mempertaruhkan aset tunggal miliknya, tanah sebagai cagaran untuk memerangi cengkaman raja. Pak Kaduk juga seorang yang optimis dan yakin bahawa dia akan menang dan pandai membuat keputusan dalam jangka masa yang sangat singkat. Sinisisme ini secara tegas menyatakan bahawa semua masalahnya yang datang biasanya disebabkan oleh kelalaian diri. Aplikasi ini adalah bentuk nasihat ketika melakukan sesuatu untuk menggunakan akal dan berhati-hati. Hal ini jelas menunjukkan sikap Pak Kaduk terburu-buru membuat sendiri keburukan. Akibat tidak berfikir secara mendalam, dia kehilangan tanah dan menyebabkan dia menetap di rumah orang lain. Berdasarkan seloka Pak Kaduk di atas, penulis cuba untuk menyampaikan teguran dalam bentuk sindiran halus kepada masyarakat agar tidak melakukan perbuatan seperti Pak Kaduk. Hal ini kerana, perbuatannya yang mendatangkan kerugian kepada diri malah keluarganya sendiri. Sebagaimana petikan "ayamnya menang kampung tergadai" menjelaskan bahawa sikap Pak Kaduk yang suka berjudi yang tiada manfaat telah membawa kerugian kepada diri sendiri. Secara intrinsiknya membuktikan kebijaksanaan masyarakat dalam bentuk sindiran yang berbentuk halus tetapi tidak menyakitkan hati sesuai diguna pakai dalam mendalami pemikiran masyarakat. Walau bagaimanapun, seloka ini banyak memberi nilai dan pengajaran yang baik untuk rujukan masyarakat sebelum bertindak melakukan sesuatu perkara. Oleh itu, dengan penggunaan gaya bahasa secara sindiran melalui seloka ini 
mampu membawa mesej kepada masyarakat agar sentiasa melakukan sesuatu perkara dengan bijak dan berakal supaya tidak mudah ditipu oleh orang lain.

\section{KESIMPULAN}

Kesimpulannya, seloka merupakan sindiran tajam terhadap masyarakat yang bertindak siasia dan tidak menggunakan kewarasan fikiran dalam tindakan. Kelemahan membuat keputusan dan tidak menggunakan pertimbangan akal yang waras akan mendatangkan kerugian. Di samping itu, seloka sebenarnya dikarang untuk menyampaikan kritikan dan sindiran terhadap sesuatu kepincangan yang berlaku dalam sesebuah masyarakat. Kritikan dan sindiran ini tajam serta disampaikan secara berlapik dan berkias dalam nada bergurau. Melalui seloka ini juga dapat menjelaskan budaya masyarakat Melayu yang tidak mengkritik secara terus tetapi dengan menggunakan cara yang halus. Kata-kata yang digunakan dalam seloka ini juga adalah lambang yang mengandungi makna yang tersirat. Oleh hal yang demikian, pengarang menggunakan perbandingan dan perumpamaan supaya setiap kiasan yang dilontarkan itu mampu memberi kesan kepada jiwa masyarakat. Justeru itu, kebodohan disebabkan oleh sikap terburu-buru, tidak rasional, tidak berfikiran terbuka, tidak mempunyai kemahiran dan ilmu, serta bertindak mengikut emosi boleh mendatang musibah terhadap diri sendiri dan masyarakat. Selain itu, penampilan kepelbagaian laras bahasa terutamanya bahasa sindiran merupakan elemen komunikasi yang berkesan dalam menyampaikan sesuatu ujaran secara berkias agar pihak yang menerima teguran itu mampu berfikir secara mendalam di sebalik kata-kata yang diujarkan kepada mereka. Keindahan laras atau gaya bahasa sindiran menerusi seloka turut menggambarkan ketinggian penyampaian masyarakat Melayu bagi menjaga sensitiviti atau perasaan seseorang ketika proses komunikasi berlangsung.

\section{BIODATA}

Dr. Nordiana Binti Ab Jabar merupakan pensyarah kanan di Jabatan Warisan, Fakulti Teknologi Kreatif dan Warisan, Universiti Malaysia Kelantan (UMK). Bidang pengkhususan ialah kesusasteraan Melayu dan fokus kajian terkini ialah puisi tradisional Melayu serta multimedia dalam kesusasteraan Melayu. E-mel: nordiana.aj@umk.edu.my

Mohd Faradi bin Mohamed Ghazali merupakan pensyarah di Pusat Pengajian Bahasa Moden dan Komunikasi, Fakulti Bahasa dan Komunikasi, Universiti Sultan Zainal Abidin. Beliau juga merupakan pelajar ljazah Doktor Falsafah (Phd) di Universiti Malaysia Kelantan. Bidang pengkhususan ialah Kesusasteraan Melayu moden (Teori, Kritikan Sastera dan Penulisan Kreatif). E-mel: faradighazali@unisza.edu.my 


\section{RUJUKAN}

Athirah Abdul Rahim. (2015). Satira kesusasteraan dalam konteks sosiobudaya India (India): Kajian terhadap filem 3 Idiots (2009) dan Pk (2014). UiTM.

Arba'ie Sujud. (2010). Apresiasi bahasa: Interpretasi dan ekspresi. DBP.

Asmah Haji Omar. (1997). Bahasa laporan. Dewan Bahasa dan Pustaka.

Darmawan, K. Z. (2008). Penelitian etnografi komunikasi: Tipe dan metode. Jurnal Komunikasi, 9(1), 181-188.

Azlina Abdullah, Nor Azlili Hassan, Novel Lyndon, Nur Hafizah Yusoff, \& Ummi Munirah Syuhada Muhamad. (2019). Ethnicity at workplace: Value and culture of Malaysian Malay tradition in organization. International Journal of Advanced and Applied Sciences, 6(11), 92-101.

Darus Ahmad. (1960). Alam puisi Melayu. Sinaran Bros Limited.

Enida Daud. (2019). Faktor-faktor dalaman yang mempengaruhi niat individu untuk mengamalkan rasuah di Kalangan penjawat awam pihak berkuasa tempatan. UTM.

Faizul Nizar Anuar, Fauziah Ahmad, \& Sabariah Mohamed Salleh. (2018). Meme sebagai seloka persendaan dan parodi: Impak dimensi sosiobudaya. JKMJC, 34(1), 75-96.

Fasold, R., Yamada, H., Robinson, D., \& Barish, S. (1990). The language-planning effect of newspaper editorial policy: Gender differences in the Washington Post. Language in Society, 19(4), 521-539.

Ghazali Lateh, \& Shamsudin Othman, S. (2016). Tinjauan interaksi lisan bahasa Melayu dalam kalangan remaja Malaysia dari sudut etnografi komunikasi. JPBM, 4(1), 30-40.

Halimah, S. N., \& Hilaliyah, H. (2019). Gaya bahasa sindiran Najwa Shihab dalam buku catatan Najwa. DEIKSIS, 11(02), 157-165.

Harun Mat Piah. (1989). Puisi Melayu tradisional satu pembacaan genre dan fungsi. DBP.

Hymes, D. (Ed.). (1964). Languagein culture and society: A reader in linguistics and anthropology. Harper \& Row.

Hymes, D. (1967). The anthropology of communication. In Dance, F. E. X. (Ed.), Human communication theory: Original essays. Holt, Rinehart \& Winston.

Hymes, D. (1972). Models of the interaction of language and social life. In J. Gumperz \& D. Hymes (Eds.), Directions in sociolinguistics: The ethnography of communication. Wiley-Blackwell.

Hymes, D. (1974). Foundations in sociolinguistics: An ethnographic approach. University of Pennsylvania Press.

Kamarudin Arim. (2004). Korupsi dan pembangunan: Kajian kes tentang rasuah di Malaysia [Tesis Sarjana, Universiti Malaya, Kuala Lumpur].

Keraf, G. (2007). Diksi dan gaya bahasa. PT Gramedia Pustaka.

Md. Sabri Che Man. (2004). Wacana wawancara formal bahasa Melayu: Satu kajian etnografi komunikasi [Tesis Doktor Falsafah, Universiti Putra Malaysia].

Mohd Faradi Mohamed Ghazali, \& Mohd Fairuz Mohd Padoli. (2016). Bauran satira dalam Pak Pandir moden. Proceeding of Workshop on High Impact Journal Writing and Publishing 2016, 1(1), 111-130.

Mohammad Fadzeli Jaafar. (2016). Gaya ujaran dalam teks kesusasteraan Melayu. JKMJC, 32(2), 341-361.

Mohamad Mokhtar Abu Hassan. (2013). Pendekatan pengurusan: Satu metode dalam kritikan sastera. Himpunan Ilmuwan Sastera Melayu Malaysia Kedua Universiti Perguruan Sultan Idris, 4-5. 
Mohamad Zuber Ismail, Sara Beden dan Mohamad Mokhtar Abu Hassan. (2015). Hikayat Awang Sulung Merah Muda dari perspektif pendekatan pengurusan. Jurnal Pengajian Melayu, 26, 96-116.

Mokodongan, A. (2015). Gaya bahasa sindiran pada acara Sentilan Sentilun di Metro TV Tahun 2015. Universitas Negeri Gorontalo.

Mukhlis Abu Bakar. (2008). Pengalaman literasi, wacana bilik darjah dan pencapaian akademik: Suatu perspektif sosiobudaya. Jurnal e-Utama, 1, 43-59

Nordiana Ab Jabar. (2019). Keunggulan ikon membawa teladan dalam seloka Melayu. Rumpun Jurnal Persuratan Melayu, 7(1), 172-191.

Nor Hasimah Ismail, Melor Fauzita Md. Yusoff, Nazilah Mohamad, \& Julizayati Shukor. (2017). The human capital in seloka Pak Kaduk [conference presentation]. 1st International Conference on Intellectuals' Global Responsibility (ICIGR 2017).

Noor Hasnoor Mohamad Nor, Eizah Mat Hussain, \& Ahmad Ramizu Abdullah. (2019). Kesopanan dalam komunikasi menerusi filem animasi kanak-kanak tempatan. Jurnal Komunikasi: Malaysian Journal of Communication, 35(4), 368-385.

Nurul Halimah, \& Hilda Hilaliyah. (2019). Gaya bahasa sindiran Najwa Shihab dalam buku Catatan Najwa. Universitas Indraprasta PGRI.

Philips, S. U. (1972). Participant structures and communicative competence: Warm Springs children in community and classroom. In L. Monaghan, J. E. Goodman, \& J. M. Robinson (Eds.), A cultural approach to interpersonal communication: Essential readings (pp. 395-410). Blackwell Publishing.

Prameswari, J. Y. (2019). Gaya bahasa sindiran pada bahasa iklan penyedia layanan jaringan telepon. Universitas Indraprasta PGRI.

Rahmat Selisih Mara, \& Rajab Bahry. (2019). Analisis gaya bahasa sindiran dalam syair Didong Jalu Arita Mude dan Biak Cacak. Universitas Syiah Kuala.

Sahlan Mohd. Saman, \& Saiful Bahri Md. Radzi. (2005). Persuratan Melayu tradisional ke moden. Penerbit Universiti Kebangsaan Malaysia.

Shaiful Bahri Md. Radzi. (2005). Tradisi bertulis: Prosa. Dlm. Sahlan Mohd. Saman, \& Shaiful Bahri Md. Radzi (pnyt.), Persuratan Melayu tradisional ke moden. Penerbit UKM.

Saville-Troike, M., \& Kleifgen, J. (1989). Culture and language in classroom communication. In Garcia, O., \& Otheguy, R. (Eds.), English across cultures, cultures across English: A reader in cross-cultural communication (pp. 83-102). Mouton de Gruyter.

Schiffrin, D. (1994). Making a list. Discourse processes, 17(3), 377-406.

Siti Komariya. (2015). Novel Nayla karya Dijenar Maesa Ayu: Kajian stilistika [Undergraduate thesis, Universitas Jember]. http://repository.unej.ac.id/handle/123456789/72557

Siti Norsyahida Mohd A. Rashid, \& Nor Azuwan Yaakob. (2017). Jenis bahasa sindiran dalam ujaran vlog. IJLEAL, 7(Dec). https://journal.ump.edu.my/ijleal/article/511

Spender, D. (1980). Man made language. George Routledge.

Tarigan, H. G. (1985). Pengajaran gaya bahasa. Angkasa.

Ungku Abdul Aziz. (2011). Pantun dan kebijaksanaan akal budi Melayu. KL: DBP.

Wahyuni, E. R., \& Subandi. (2018). Penggunaan gaya bahasa sindiran dalam Film Xiao Haizi Bu Ben 2. Universitas Negeri Surabaya.

Winstedt, R. (1969) A history of classical Malay literature. Oxford.

Zainal Abidin Ahmad (Za'ba). (1965). Ilmu mengarang Melayu. Dewan Bahasa dan Pustaka.

Zainal Abidin Ahmad (Za'ba). (2002). Ilmu mengarang Melayu: Edisi ejaan rumi baharu dengan pengenalan oleh Asmah Haji Omar. Dewan Bahasa dan Pustaka. 